\title{
Mobil Konutlarda Suyun Etkin Kullanımının Su Yönetimi Açısından Değerlendirilmesi
}

\author{
Seda SOLAKOĞLU1, Gözde ÇAKIR KIASIF
}

Öz

Sanayi Devrimiyle birlikte kaynakların savurganca kullanılması sonucu ortaya çıkan çevresel sorunlara bir çözüm önerisi olarak ortaya çıkan sürdürülebilirlik kavramı yapı teknolojilerinin gelişmesi ve kullanıcı intiyaçlarının evirilmesi ile sürdürülebilir mimari alanında da önemini ortaya koymuştur. Mobil konut kavramı ise sürdürülebilir tasarım anlayışını bünyesinde barındıran, çevreci, doğa ile bütünleşmeye imkan veren, taşınabilir, esnek-değişebilir-dönüşebilir bir konut tipi olarak günümüzde belli bir kesim tarafından tercih edilmektir. 21.yüzyıldan bu yana kontrolsüz nüfus artışı ve akabinde artan su talebine karşı suyun kısıtıığı, yanlış kullanılması ve doğru yönetilememesi sonucunda su krizleri yaşanmaya başlamıştır. Bu durum yapılarda da suyun etkin kullanımının önemini ortaya çıkarmıştır. Çalışmanın amacı, su yönetimi açısından mobil konutlarda su etkin stratejiler ve yöntemlerle ciddi su tasarrufları elde edilebileceğini ortaya koymaktır. Çalışmada yöntem olarak literatür taraması yapıımıştır. Ayrıca ilgili kurum ve bakanlıklarca bu konu ile ilgili ortaya konan raporlar incelenerek Türkiye'nin Su potansiyeli, su kaynakları, su politikaları ve su verimliliği üzerine araştırmalar yapılmıştır. Bu kapsamda klasik bir mobil konut ile su etkin sistemlerle donatılmış bir mobil konuttaki yıllık su tüketimi karşılaştırılmıştır. Dört kişilik bir ailenin su tüketiminde 229631 litre su tasarrufu elde edilebileceği ortaya konup su yönetimi açısından önemine değinilmiştir.

Anahtar Kelimeler: Su Yönetimi, Su Etkinliği, Mobil Konutlar

\section{The Importance of Effective Use of Water in Mobile Homes in terms of Water Management}

\begin{abstract}
The concept of sustainability, which emerged as a solution to the environmental problems that emerged as a result of the wasteful use of resources with the Industrial Revolution, has also revealed its importance in the field of sustainable architecture with the development of building technologies and the evolution of user needs. The concept of mobile housing, on the other hand, is preferred by a certain group of people today as a portable, flexible-changeable-transformable housing type that incorporates a sustainable design concept, is environmentally friendly, allows integration with nature. Since the 21st century, water crises have arisen as a result of the uncontrolled population growth and the consequent increase in water demand, as a result of the limitation, misuse and improper management of water. This situation has revealed the importance of effective use of water in buildings. The aim of the study is to reveal that serious water savings can be achieved with water efficient strategies and methods in mobile homes in terms of water management. In the study, a literatüre review was made as a method. In addition, studies on Turkey's water potential, water resources, water policies and water
\end{abstract}

\footnotetext{
${ }^{1}$ Haliç Üniversitesi, Lisansüstü Eğitim Enstitüsü, Mimarlık Ana Bilim Dalı, İstanbul, Türkiye.

${ }^{2}$ Haliç Üniversitesi, Mimarlık Fakültesi, Mimarlık Bölümü, İstanbul, Türkiye

Bu çalışma, Haliç Üniversitesi, Lisansüstü Eğitim Enstitüsü, Mimarlık Anabilim Dalı, Mimarlık Programında tamamlanan "Su Yönetimi Kapsamında Mobil

Konutlarda Suyun Etkin Kullanılmasının Sürdürülebilir Kalkınma Açısından Değerlendirilmesi” başlıkı yüksek lisans tezinden üretilmiştir.

İlgili yazar/Corresponding author: gozdecakir@halic.edu.tr 
efficiency were carried out by examining the reports prepared by the relevant institutions and ministries on this subject. In this context, annual water consumption in a conventional mobile home and a mobile home equipped with water efficient systems was compared. It has been revealed that 229631 liter of water can be saved in the water consumption of a family of four and its importance in terms of water management is mentioned.

Keywords: Water Management, Water Efficiency, Mobile Homes

\section{Giriş}

İnsanoğlu varoluşun başından bu yana doğal koşullarla mücadele etmiştir. Hayatta kalabilmek amacıyla yapılan ilk binalar taşınabilir konutlar ve geçici sığınaklar olmuştur. $\mathrm{Bu}$ anlamda, insanlık tarihinde hareketli yapıların ilk tasarımı, doğal koşullara karşı savaşan insanların geçici konaklama birimi olarak ortaya çıkmıştır. Bu tür yapıların temel unsuru; dış hava şartlarından ve etraftaki tehlikelerden koruması yönünde olmuştur. Göçebe kültürün etkisiyle barınma ve korunmanın yanı sıra taşınabilen hareketli evlere intiyaç duyan insan toplulukları ilk mobil konutların ortaya çıkmasına vesile olmuştur. İlk mobil yapıları meydana getiren insanlar mobilitenin ve konut için konumun öneminin farkında olmuşlardır.

Son yıllarda küresel ısınma ve iklim değişikliği sorunu, ekosistem üzerindeki olumsuz etkilerini net bir şekilde hissettirerek sürdürülebilirliği tehdit etmektedir. Gelişen teknolojiyle birlikte kaynakların savurganca kullanılmasından dolayı ortaya çıkan küresel ısınma sorunu akabinde buzulların erimesi, deniz seviyesinin artması, erozyon, sel, biyolojik çeşitliliğin azalması, kuraklık ve tatı su kaynaklarının tahribatı gibi çevresel felaketlere neden olmuştur (Kadıoğlu, 2007; Çakır, 2012: 455). Bu sorunlarla mücadele edebilmek adına devletlerarası bazı protokoller ve anlaşmalar imzalanarak sektörel kısıtlamalar getirilmiştir. Yapı sektörü de enerjiyi, suyu ve malzemeyi kontrolsüzce tüketen ve çevresel sorunlara neden olan baş sektörlerden biri olduğu için sürdürülebilir teknolojileri benimsemek durumunda kalmıştır. Özellikle dünyada çok kısıtlı bir oranda bulunan tatı su kaynaklarının korunumu ve verimli kullanımı, sağlıklı bir çevrede yaşayabilmek adına hayati bir önem taşımaktadır. Bu bağlamda yapıların tüm yaşam döngüleri boyunca suyu etkin kullanabilmesi sürdürülebilirlik ve su yönetimi adına çok önemli bir husustur.

Birleşmiş Milletler Dünya Su konseyi (UNCWW), Dünya Kaynakları Enstitüsü (IWR) ve Dünya Sağlık Örgütü (WHO) gibi kuruluşlar su ile yapmış oldukları araştırmalarda 1950 'lerde sadece birkaç ülkenin su sıkıntısı yaşadığını, 1990'larda ise bu oranın çok hızlı ve kontrolsüzce artarak 26 ülkede su sıkıntısının yaşandığını ortaya koymuşlardır. $\mathrm{Ne}$ yazık ki yeterli önlemlerin alınmaması halinde 2050 senesinde dünya nüfusunun 2/3'ünün ciddi su sıkıntısı çekeceği ve 66 ülkede su krizlerinin yaşanacağı öngörülmektedir (URL-1). Küresel ısınma, yanlış ve kontrolsüz su tüketimi sonucu kullanılabilir su kaynaklarının kademeli olarak azalması küresel gündemde su sorununu ilk sıraya taşımaktadır. Su yönetimi kapsamında tarımsal, endüstriyel ve evsel kullanım için su kaybını önleme, verimli su kullanımı ve havzadaki su kaynaklarının geliştirilmesi büyük önem arz etmektedir (Aküzüm ve Çakmak, 2008:67). Yapı sektörü suyun etkin kullanımı adına yağmur sularını ve gri suları değerlendirerek, doğal peyzaj uygulamalarına tasarımlarında bol bol yer vererek ve su etkin ekipman kullanarak yıllık bazda ciddi su tasarrufu elde edebilmektedir.

Çalışma kapsamında mobil konutlarda su etkin sistemler ele alınarak yıllık bazda ne kadar tasarruf elde edileceği ortaya irdelenecektir. Çalışmanın amacı mobil konutların 
klasik sistemler yerine su etkin sistemlerle donatılmasının su yönetimi açısından önemini ortaya koymaktır. Ayrıca mobil konutlarda kullanılan sistemler diğer yapı türleri içinde benzerlikler göstermekte ve uygulama alanı bulmaktadır. Çalışmada yöntem olarak literatür taraması yapılarak önemli indekslere sahip yayınlar taranmış ve güncel sempozyum-kongreler takip edilerek konu ile ilgili bildiriler incelenmiştir. T.C. Kalkınma Bakanlığının On Birinci Kalkınma Planı (2019-2023) - Su Kaynakları ve Güvenliği Özel İhtisas Komisyonu Raporunda Türkiye'nin su potansiyeli, su kaynakları, su politikaları, sektörel kullanımlar, su kalitesi, su verimliliği ile ilgili konular araştırılarak yapı sektörünün yapabilecekleri ve üzerine düşen sorumlulukları ele alınacaktır.

\section{Kuramsal Çerçeve}

\subsection{Su yönetimi ve Türkiye'nin mevcut durum analizi}

Su yönetimi, su kaynaklarının planlı gelişimi, dağıtımı ve kullanımı olarak tanımlanmaktadır. Su yönetimi, evsel, tarımsal ve endüstriyel su kullanımının yanı sıra su kalitesi, atık su kullanımı, su hukuku, sağlık ve uluslararası hukuk gibi birçok alanı kapsamaktadır. Gıda güvenliğini sağlamak, günümüz ve gelecekteki ihtiyaçları karşılamak adına birçok ülkede entegre yönetim yaklaşımı benimsenmektedir. Su kaynaklarının sadece fiziksel değil, aynı zamanda sosyal, ekonomik ve çevresel faktörleri de içeren bir perspektifte ele alınması gerektiği netlik kazanmıştır. Entegre yönetimin temeli, suyun bir doğal kaynak aynı zamanda kullanım kalite ve miktarına göre değişebilen bir olgu olarak kabul edilmesidir. Su kayıplarının önlenmesi, suyun verimli kullanılması, yeni su tasarrufu teknolojilerinin uygulanması ve su tüketen sektörlerde havza düzeyinde su kaynaklarının geliştirilmesi giderek daha fazla önem kazanmaktadır (Aküzüm ve Çakmak, 2008: 68). Su krizine çözüm bulabilmek adına Avrupa Birliği sürdürülebilir su politikaları üzerine çalışmalar yürütmüş ve Su Çerçeve Direktifi (SÇD) ile 2000 yılının sonunda havza bazlı yönetim yaklaşımının doğru olduğunu savunmuştur. $\mathrm{Bu}$ direktife göre su kaynaklarının miktar ve kalite bağlamında korunup kontrol edilmesinin önemine değinilerek tüm paydaşların aktif katılımı ile yüzeysel ve yeraltı sularının iyileştirilmesi hedeflenmiştir (T.C. Kalkınma Bakanlığı, 2018: 6).

Dünyadaki toplam su miktarının \%97,5'ini okyanus ve denizler oluşturmaktadır. Buzullar ve tuzlu yeraltı sularını da çıkardığımızda güvenli tüketebileceğimiz tatı su kaynakları \%2,5 gibi kısıtlı bir oranda kalmaktadır (Yılmaz, 2015: 63). Bunun yanında artan nüfus, küresel ısınma gibi sorunlar ve tatlı su kaynaklarının dünyadaki dengesiz dağılımı neticesinde ülkelerin su politikaları ve suyun doğru yönetilebilmesi büyük önem arz etmektedir.

Ülkemizdeki toplam yıllık su akımının yarısına yakını 25 havzanın beşinde (Fırat, Dicle, Doğu Akdeniz, Doğu Karadeniz ve Antalya) bulunmaktadır. Bu beş havzanın dışında kalan 20 havza, toplam su akışının kalan diğer yarısını paylaşmaktadır (Çizelge 1). Fırat ve Dicle havzalarının oranı tek başına toplam akışın yaklaşık \%30'unu oluşturmaktadır (Usta, 2016: 2). Bu durum suyun havzalara dağılımında eşitsizlik olduğunun bir göstergesidir. Öte yandan, havzaların akışı ile hizmet ettikleri nüfus arasında bazı dengesizlikler de bulunmaktadır. Örneğin, toplam nüfusun \%28'ine ev sahipliği yapan Marmara havzası, toplam akışın yalnızca \%4'üne sahiptir. Benzer şekilde Sakarya, Büyük Menderes, Küçük Menderes, Konya Kapalı Havzası, Kızılırmak gibi havzalarda akış miktarı ile hizmet verilen nüfus arasındaki oran açısından önemli farklıııklar bulunmaktadır. Bu durum havzalarda su kullanımını etkilemekte ve su kıtlığına neden olmaktadır (URL-2). 
Mobil Konutlarda Suyun Etkin Kullanımının Su Yönetimi Açısından Değerlendirilmesi

The Importance of Effective Use of Water in Mobile Homes in terms of Water Management

Çizelge 1. Türkiye'deki Havzalara Göre Yıllık Ortalama Su Potansiyelleri - 2019 (URL-2)

\begin{tabular}{|c|c|c|c|c|}
\hline \multicolumn{5}{|c|}{ Havzalara Göre Yıllık Ortalama Yüzeysuyu Su Potansiyeli (2019) } \\
\hline \multirow[b]{2}{*}{$\begin{array}{c}\text { Havza } \\
\text { No }\end{array}$} & \multirow[b]{2}{*}{ Havzanin Adı } & \multicolumn{3}{|c|}{2019} \\
\hline & & $\begin{array}{c}\text { Havza } \\
\text { Yağıșalanı } \\
\left(\mathrm{km}^{2}\right)\end{array}$ & $\begin{array}{c}\text { Ortalama } \\
\text { Yıllık Akıș } \\
\left(\mathrm{km}^{3}\right)(* \cdots *)\end{array}$ & $\begin{array}{c}\text { Potansiyel } \\
\text { İștirak Oranı } \\
(\%)\end{array}$ \\
\hline 01 & Meriç Ergene & $14.486,0$ & 1,7 & 0,9 \\
\hline 02 & Marmara & $23.074,0$ & 7,4 & 4,0 \\
\hline 03 & Susurluk & $24.319,0$ & 5,0 & 2,7 \\
\hline 04 & Kuzey Ege & $9.861,0$ & 2,0 & 1,1 \\
\hline 05 & Gediz & $17.137,0$ & 1,8 & 1,0 \\
\hline 06 & Küçük Menderes & $6.963,0$ & 0,6 & 0,3 \\
\hline 07 & Büyük Menderes & $25.960,0$ & 3,0 & 1,6 \\
\hline 08 & Bat1 Akdeniz & $20.956,0$ & 6,5 & 3,5 \\
\hline 09 & Antalya & $20.249,0$ & 12,9 & 7,0 \\
\hline 10 & Burdur Göller & $6.294,0$ & 0,2 & 0,1 \\
\hline 11 & Akarçay & $7.995,0$ & 0,4 & 0,2 \\
\hline 12 & Sakarya & $63.303,0$ & 6,5 & 3,5 \\
\hline 13 & Bat1 Karadeniz & $28.855,0$ & 10,8 & 5,8 \\
\hline 14 & Yeşilırmak & $39.595,0$ & 7,0 & 3,8 \\
\hline 15 & Kizilirmak & $82.181,0$ & 7,0 & 3,8 \\
\hline 16 & Konya Kapalı & $49.930,0$ & 2,4 & 1,3 \\
\hline 17 & Doğu Akdeniz & $21.150,0$ & 7,6 & 4,1 \\
\hline 18 & Seyhan & $22.035,0$ & 6,2 & 3,3 \\
\hline 19 & Asi & $7.886,0$ & 1,8 & 1,0 \\
\hline 20 & Ceyhan & $21.391,0$ & 7,7 & 4,2 \\
\hline 21 & Firat-Dicle & $176.143,0$ & 56,3 & 30,4 \\
\hline 22 & Doğu Karadeniz & $22.846,0$ & 16,4 & 8,9 \\
\hline 23 & Çoruh & $20.248,0$ & 7,0 & 3,8 \\
\hline 24 & Aras & $27.775,0$ & 4,5 & 2,4 \\
\hline 25 & Van Gölü & $17.861,0$ & 2,6 & 1,4 \\
\hline & Toplam & 778.493 & 185,37 & 100 \\
\hline
\end{tabular}

\begin{tabular}{|c|c|c|c|}
\hline \multicolumn{4}{|c|}{ Havzalara Göre Yıllık Yeraltısuyu Potansiyeli (2019) } \\
\hline \multirow[b]{2}{*}{ Havza No } & \multirow[b]{2}{*}{ Havza Adı } & \multicolumn{2}{|c|}{2019} \\
\hline & & $\begin{array}{c}\text { Yeraltısuyu } \\
\text { Beslenimi }\end{array}$ & $\begin{array}{c}\text { Yeraltısuyu İșletme } \\
\text { Rezervi }\end{array}$ \\
\hline 1 & Meriç - Ergene & 507,7 & 498,2 \\
\hline 2 & Marmara & 241,7 & 210,7 \\
\hline 3 & Susurluk & 780,4 & 585,9 \\
\hline 4 & Kuzey Ege & 289,4 & 212,9 \\
\hline 5 & Gediz & 1155,9 & 866,9 \\
\hline 6 & Küçük Menderes & 179,2 & 179,2 \\
\hline 7 & Büyük Menderes & 1045,4 & 761,5 \\
\hline 8 & Bat1 Akdeniz & 473,2 & 316,7 \\
\hline 9 & Antalya & 1164,7 & 576,3 \\
\hline 10 & Burdur Göller & 106,4 & 89,5 \\
\hline 11 & Akarçay & 345,4 & 345,4 \\
\hline 12 & Sakarya & 2197,1 & 1545,2 \\
\hline 13 & Batı Karadeniz & 641,2 & 607,6 \\
\hline 14 & Yeșilırmak & 907,2 & 872,8 \\
\hline 15 & Kizilirmak & 2003,1 & 1762,9 \\
\hline 16 & Konya Kapalı & 2597,0 & 2023,0 \\
\hline 17 & Doğu Akdeniz & 96,5 & 70,5 \\
\hline 18 & Seyhan & 838,8 & 749,9 \\
\hline 19 & Asi & 393,2 & 289,5 \\
\hline 20 & Ceyhan & 985,3 & 533,5 \\
\hline 21 & Firat - Dicle & 4994,8 & 3763,7 \\
\hline 22 & Doğu Karadeniz & 490,9 & 490,9 \\
\hline 23 & Çoruh & 30,0 & 20,0 \\
\hline 24 & Aras & 388,5 & 294,4 \\
\hline 25 & Van Gölï & 179,2 & 148,2 \\
\hline & Toplam & 23032,3 & 17815,3 \\
\hline
\end{tabular}

Ülkemiz, kişi başına düşen $1366 \mathrm{~m}^{3}$ kullanılabilir su miktarı ile su kısıtı (su baskısı) bulunan ülkeler kategorisinde yer almaktadır. Türkiye $112 \mathrm{~km}^{3}$ lük kullanılabilir su potansiyeline sahiptir. Mevcut tüketim ise $54 \mathrm{~km}^{3}$ ile bu tutarın \%48'i kadardır. Bu tutarın $39 \mathrm{~km}^{3}$ 'ü yerüstü sularında, $15 \mathrm{~km}^{3}$ 'ü ise yeraltı sularından sağlanmaktadır. Suyun sektörler arası dağılımına bakıldığında ise $40 \mathrm{~km}^{3}(\% 74)$ ile tarımsal sulama, $7 \mathrm{~km}^{3}(\% 13)$ ile yeme-içme-evsel faaliyetler diğer $7 \mathrm{~km}^{3}(\% 13)$ ile endüstriyel faaliyetler yer almaktadır (T.C. Orman ve Su İşleri Bakanlığı-2.Ormancılık ve Su Şurası,2017: 27; Çakır Kıasıf, 2020: 102).

Türkiye İstatistik Kurumu'nun (TUIK) 2018 Belediye Su İstatistikleri raporunda içme ve kullanma suyu şebekelerinden 6,2 milyar $\mathrm{m}^{3}$ su çekildiği görülmektedir. Bu suların $\% 39,9$ 'u barajlardan, \%28,1'i kuyulardan, \%18,4'ü kaynaklardan, \%9'u akarsulardan ve \%4,6'sı göl, gölet ve denizlerden temin edilmiştir. Bu suyun 3,6milyar $\mathrm{m}^{3}$ 'ü konvansiyonel, gelişmiş ve fiziksel arıtma ile arıtılmıştır. İçme ve kullanma suyu şebekesinden kişi başı günlük ortalama 224 It su çekildiği görülmüştür (Çizelge 2) (URL$3)$. 
Çizelge 2. Belediye Su İstatistikleri - 2018 (URL-3)

Belediye su göstergeleri, 2016, 2018

\begin{tabular}{|c|c|c|}
\hline & 2016 & 2018 \\
\hline Toplam belediye sayısı & 1397 & 1399 \\
\hline İçme ve kullanma suyu şebekesi ile hizmet verilen belediye sayısı & 1394 & 1397 \\
\hline $\begin{array}{l}\text { İçme ve kullanma suyu şebekesi ile hizmet verilen nūfusun } \\
\text { toplam belediye nüfusuna oranı (\%) }\end{array}$ & 98,2 & 98,6 \\
\hline İçme ve kullanma suyu şebekesi için çekilen toplam su miktarı (milyon m³) & 5839 & 6193 \\
\hline \multicolumn{3}{|l|}{ İçme ve kullanma suyu şebekesi için çekilen suyun kaynaklarına göre dağılımı (\%) } \\
\hline Baraj & 44,8 & 39,9 \\
\hline Kuyu & 26,8 & 28,1 \\
\hline Kaynak & 17,1 & 18,4 \\
\hline Akarsu & 9,5 & 9,0 \\
\hline Göl/gölet/deniz & 1,8 & 4,6 \\
\hline İçme ve kullanma suyu șebekesi ile dağıtılan su miktarı (milyon $\mathrm{m}^{3}$ ) & 3733 & 4045 \\
\hline İçme ve kullanma suyu aritma tesislerinde aritılan su miktarı (milyon $\mathrm{m}^{3}$ ) & 3350 & 3574 \\
\hline Kiși bașı çekilen günlük ortalama su miktan (litre/kiși-gün) & 217 & 224 \\
\hline
\end{tabular}

\subsection{Sürdürülebilir yapı tasarımında suyun etkin kullanımı}

Küreselleşme ile birlikte gerçekleşen kontrolsüz nüfus artışı, küresel ısınma, çevre kirliliği, bilinçsiz kaynak tüketimi gibi nedenlerle dünyanın birçok bölgesinde yoğun su sorunları yaşanmaya başlanmıştır. Sektörel su tüketim oranlarına bakıldığında yapı sektörünün de ciddi bir pay aldığı görülmekte ve su tasarrufu sağlayan stratejilerin uygulanması zorunluluğu ortaya çıkmaktadır. Sürdürülebilirlikte, sürdürülebilirlik bilincinin ve sürdürülebilir tüketim hareketinin elde edilmesi çok önemli bir husustur. Sürdürülebilir tüketim hareketi, tüketim davranışlarını farklılaştırma ve tüketim seviyesini düşürme ile mümkün olmaktadır (Karalar ve Kiracı, 2011:68; Schaefer ve Crane, 2005:78). Sürdürülebilir yapım ilkelerinden biri olan kaynakların etkin kullanımında enerji, malzeme ve doğal alanlar gibi suyun da etkin kullanılması amaçlanmaktadır. Yapılarda suyun etkin kullanımı 4 ana yöntem ile ele alınmaktadır (Sev, 2009:39). Bunlar;

- Geri dönüşüm ve yeniden kullanma

- Yağmur suyu toplama

- Doğal peyzaj uygulamaları

- Su tüketiminin azaltılması (Düşük debili, basınçıı armatürler, akıllı -susuz rezervuarlar, biyokompoze tuvaletler, vb.)

olarak sınıflandırılmaktadır.

Geri dönüşüm ve yeniden kullanma, yapılardaki gri suların değerlendirilmesi esasına dayanmaktadır. Evsel atık sulardan lavabo, duş ve küvetten gelen kirlilik oranı en düşük oranda olan suyun bir depoda toplandıktan sonra arıtılıp tekrar kullanmasıyla ciddi su tasarrufları elde edilmektedir. Bazı durumlarda mutfaktan ve çamaşır makinesinden atılan su da gri su olarak değerlendirilebilmektedir. Bu geri kazanılan sular çevre temizliğinde, bahçe sulamada, rezervuarlarda, çamaşır yıkama gibi işlerde kullanılabilmektedir (Karahan, 2009:1157). Gri suların geri dönüştürülerek tekrar kullanılabilmesi için sıhhi tesisatın ona göre düzenlenmesi gerekmektedir. Böylelikle şebeke suyu dağıtım hatlarındaki yoğunluğun azaltılması ve yüksek su tüketiminin önüne geçilmesi mümkün olacaktır.

Yağmur suyu toplama işlemi yapıların çatısına veya sert zeminine düşen suların toprak altında veya bodrum katındaki bir depoda toplanılması ve arıtılması esasına 
dayanmaktadır. Özellikle yıllık yağış miktarı yüksek olan bölgelerde yağmur sularının toplanılıp değerlendirilmesi ciddi su tasarrufları elde edilmesini sağlamaktadır. Yağmur suları, gri suların kullanıldığı tüm alanlarda alternatif bir su kaynağı olarak kullanılabilmektedir. Özellikle havaalanlarında, askeri bölgelerde, stadyumlarda, turizm yapılarında ve çatı alanı büyük olan binalarda yağmur sularının toplanarak değerlendirilmesi ile suyun korunumu adına büyük kazançlar elde edilmektedir. Birçok ülkede yağmur suları toplanıp kullanım suyu olarak tüketilerek ana şebekeden su temini alt sınırlara çekilebilmektedir. Ayrıca birçok ülkede yağmur suyu kullanımı farklı teşvik ve yasalarla desteklenerek yaygınlaştırılmaktadır (Şahin ve Manioğlu, 2011:529).

Yapıların çevresinde, çatıda veya cephede doğal peyzaj uygulamalarına yer verilmesi suyun korunumu açısında büyük önem arz etmektedir. Yerel ve endemik bitki tercihi ile hem bölgeye daha yüksek adaptasyon sağlanmakta hem de ek bir sulamaya intiyaç duyulmadan yağmur suları yeterli gelmektedir. Sulamanın gerekli olduğu durumlarda ise sprinkler sulama başlıklarıyla suyun etkin kullanımı sağlanmaktadır (Sev,2009: 43).

Yapılarda su tüketiminin azaltılmasında suyu tasarruflu kullanan rezervuarların, biyokompoze tuvaletlerin, susuz pisuarların, fotoselli-düşük debili-basınçlı armatürlerin tercih edilmesinin önemi büyüktür. Basınçlı su armatürleriyle \%30'lara varan su tasarrufu elde etmek mümkündür. Ayrıca vitrifiye seçiminde susuz pisuarlar ve biyokompoze tuvaletler ile hem su etkinliği sağlanmakta hem de şehir şebekesinin arıtma yükü hafifletilmektedir (Sev,2009: 43). Rezervuarlarda yağmur sularının ve gri suların kullanılmasının dışında intiyaca göre farklı kapasitelerde su boşaltımına imkan tanıyan modellerin tercih edilmesiyle ciddi oranda suyu kurtarmak mümkün olmaktadır.

\subsection{Mobil konut tasarımı ve sıhhi tesisat sistemi}

Tarih boyunca mobil konutlar, kullanıcılarının yaşamsal özelliklerine, coğrafi ve iklim koşullarına ve amacına göre farklı özelliklerle tasarlanmış ve geliştirilmiştir. Mobilite, bir kullanıcının coğrafi bir bölgede sosyo-ekonomik nedenlerle yer ve ikamet yerini değiştirme eğilimi olarak tanımlanabilir. En genel tanımıyla mobil konutlar, kendi bünyelerindeki hareket sistemleriyle veya farklı ulaşım araçları sayesinde taşınabilir, yeniden yerleştirilebilir ve/veya sökülüp-takılabilir tiplere sahiptir (Karaoğlu, 2014: 7).

İnsanların yaşam konforunu artırma arayışı neticesinde sürekli gelişerek günümüz hayatında sağlam bir yer edinen bu mobil konut tasarım süreci; kullanıcı kimliği, sosyokültürel yapı, yersizlik sorunu, ekonomi, ekolojik baskı ve teknolojinin ilerlemesi gibi faktörlerden etkilenmiş ve şekillenmiştir (Taşkesen, 2019: 6). Suda ve karada kullanılabilen mobil konutların bilinen en eski örnekleri olan çadırların yanı sıra karavanlar, prefabrike konutlar, modüler konutlar, geçici afet konutları, su üstü kullanımına uygun yüzer evler, konteynerler ve treylerler bu tanıma dahildir (Şekil 1) (Akbaş, 2010: 8; Taşkesen, 2019: 55). 

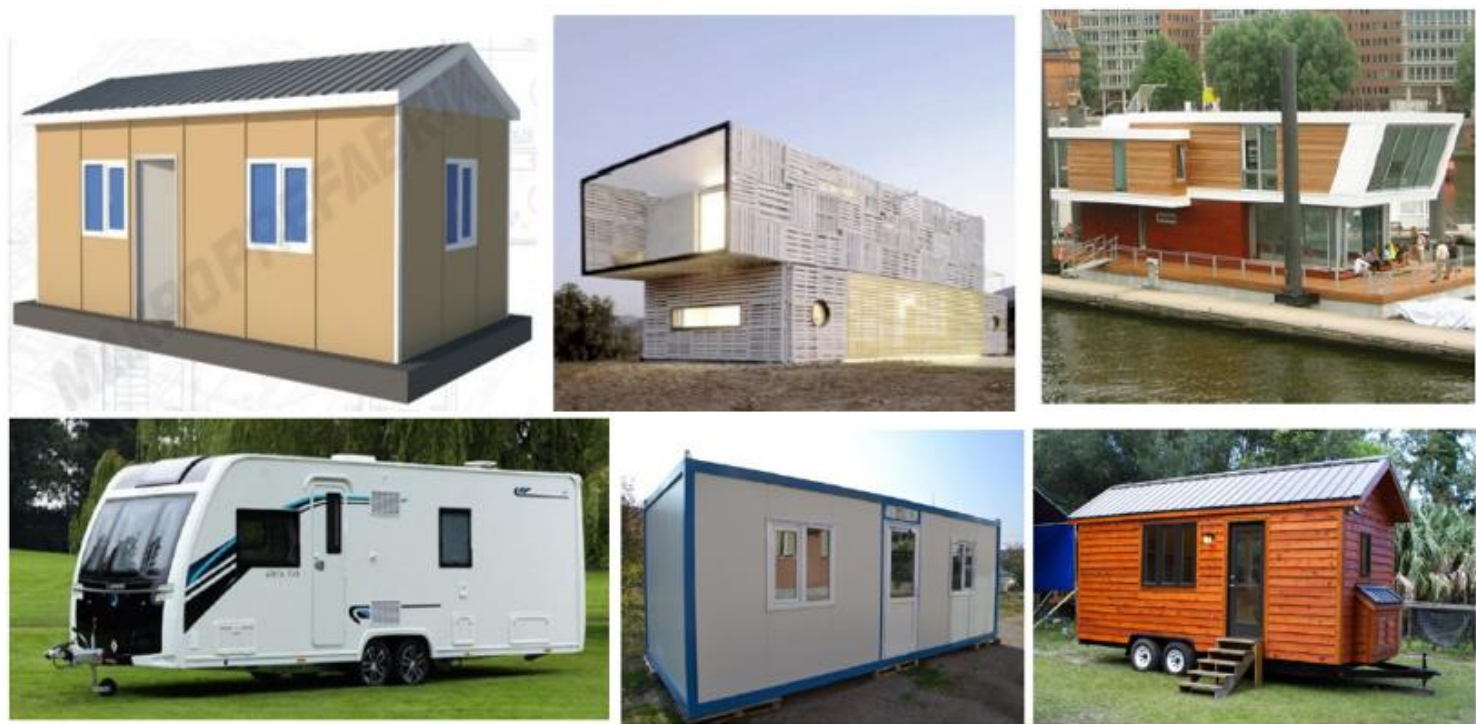

Şekil 1. Mobil Konut Türleri (Taşkesen, 2019: 56-64)

Mobil konutlarda su tesisatı genel olarak temiz su ve pis su tesisatı olarak iki bölümde ele alınmaktadır (Şekil 2). Temiz su hattında ekonomik, hijyenik, hafif, yüksek sıcaklığa dayanıklı ve kolay uygulanabilir olduğundan dolayı klorlanmış polivinil klorür (CPVC) borularının kullanılması tavsiye edilmektedir. Bu borulara alternatif olarak çapraz bağlı polietilen (PEX) ve bakır borularda kullanılabilmekte ancak kurulum aşamasındaki yaşattığı zorluklar ve maddi anlamda getirdiği yükler yüzünden çok avantajlı olmadığı görülmektedir. Ayrıca pis su hatlarında polivinil klorür (PVC) boruları, klorlanmış polivinil klorür (CPVC) borularına benzer bir performans gösterdiği için sıklıkla tercih edilmektedir (Şengül, 2019 : 125). Banyo ve mutfakta kullanılacak temiz su, ya ana şebeke bağlantısından ya da kullanıcı intiyaçları doğrultusunda uygun kapasitesi belirlenmiş temiz su depolarından temin edilmektedir.
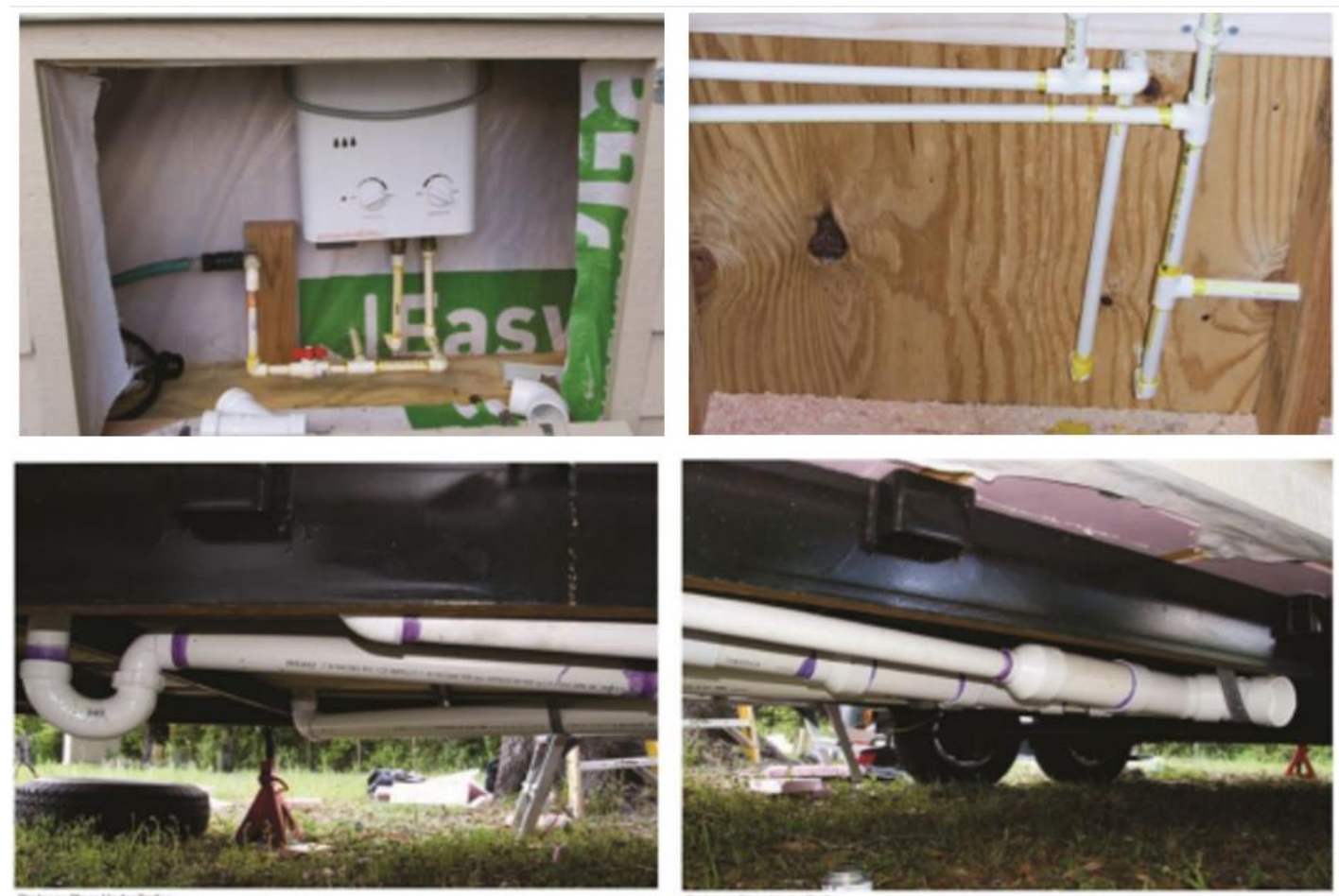

Şekil 2. Mobil Konutlarda Su Tesisatı - Temiz ve Pis Su Boruları (Louche, 2014: 110-112) 
Mobil konutlarda tuvalet kullanımı en çok endişe yaratan konulardan biridir. Mobil konutun park ettiği/konumlandığı arsada; altyapı var ise kanalizasyon şebekesinin, yok ise fosseptik çukurlarının kullanılması önerilmektedir. Bunun mümkün olmadığı yerlerde mobil konuta pis su tanklarının konulması ve belirli aralıklarla rögara atıkların boşaltılması sağlanmalıdır.

Mobil konutta sıhhi tesisat döşenirken bazı özel çözümlerin üretilmesi gerekmektedir. Örneğin atık su boruları mobil konunun alt bölümüne yerleştirilirken hafif eğim verilmeli ve her atık çıkışına suların geri gitmesini engelleyen ve bir miktar temiz suyun o kısımda tutulmasını sağlayan bir dirsek bölümü eklenmelidir. Mobil konutlarda mutfak eviyesinin ve klozetin altında mutlaka dirsek konulmalıdır ancak duş teknesinin altında böyle bir alan bulunmadığı için atık su doğrudan mobil konutun altında bulunan atık su deposuna veya altyapı mevcut ise kanalizasyona verilebilir. Bunun yanında organik atıkların yaratacağı kokunun önüne geçebilmek adına banyodaki atık su tesisatına bütünleşik havalandırma sistemi kurulmalı ve havalandırma boruları kuşların yuva yapmasını önceleyecek biçimde banyo duvarından yükseltilerek yerleştirilmelidir (Louche, 2014: 110-112).

\section{Bulgular ve Tartışma: Mobil Konutlarda Su Etkinliği}

Çevre dostu ve sürdürülebilir nitelikleriyle öne çıkan mobil konutlar, kendi su ihtiyacını karşılayabilmek için su etkin sistemleri kullanabilmektedir. Mobil konutlar suyu temin etmede eğer mevcut altyapısı var ise ana şebekeden suyu temin edebilmektedir. Alt yapının olmadığı yerlerde yağmur sularının toplanıp kullanılması mümkündür. Ayrıca mobil konut çevresinde, cephesinde veya çatısında doğal çevre ile uyumlu endemik bitki örtüsünün tercihi ciddi su tasarrufları elde edilmesini sağlamaktadır.

Diğer yapı türlerinde olduğu gibi mobil konutlarda da suyun etkin kullanımı 4 ana yöntem ile gerçekleşmektedir. Bu yöntemler; gri suların geri dönüşümü- yeniden kullanılması, yağmur sularının toplanması, doğal peyzaj uygulamaları ve su tasarrufu sağlayan batarya, vitrifiye, rezervuar, duş başıı̆ı gibi ekipman tercihidir.

\section{- Geri Dönüşüm ve Yeniden Kullanma:}

Mobil konutlarda el, bulaşık, lavabo, çamaşır yıkama, tuvalet, duş gibi yerlerde tüketilen su atık su olarak kabul edilmektedir. Bu kirli su belirli prosedürlerle arıtılıp rezervuar, araba yıkama, bahçe sulama, çevre temizliği vb. işlerde yeniden kullanılabilir (Roaf and etc., 2003: 261). Evsel atık su, binadaki kullanım yerine ve sonrasındaki geri kullanım olanaklarına göre gri ve siyah sular olarak iki grupta analiz edilmektedir.

Gri su, sulama ve farklı su koruma intiyaçları için banyolardan, duşlardan, çamaşır makinelerinden ve lavabolardan (foseptik atık hariç) boşaltılan suyun tekrar kullanılması anlamına gelir. Gri suyun doğrudan yeniden kullanımı yaygın bir uygulamadır. Banyodan çıkan gri su yüzyıllardır Avusturya, Suriye ve Güney Afrika gibi bölgelerde bahçe sulama işlerinde doğrudan kullanılmaktadır (Boyjoo ve diğ., 2013; Üstün ve Tırpancı, 2015: 123). Ayrıca günümüzde gri suyun direkt tekrar kullanımına imkan veren su tasarruflu hibrit ekipmanlar tercih edilmektedir (Şekil 3). 

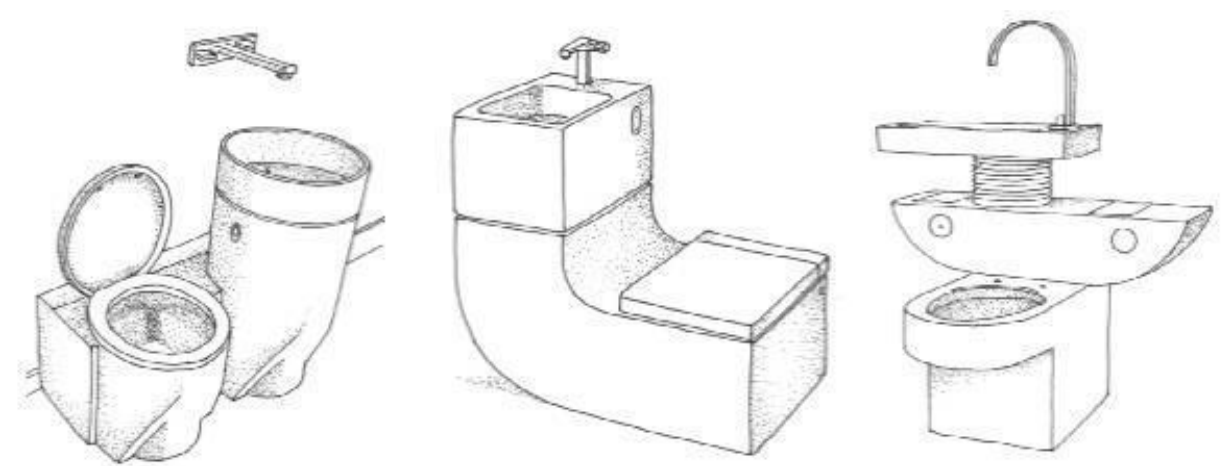

Şekil 3. Mobil konutlarda suyun tekrar kullanımını sağlayabilecek hibrit vitrifiyeler (Jaglarz, 2015: 1644)

Gri su, çeşitli bakteri ve diğer potansiyel patojenleri içerebilir. Bu nedenle güvenli kullanımını sağlamak bazı işlemlerden sonra kullanılması tavsiye edilmektedir. Gri su arıtma tesisatı kurulurken göz önünde tutulması gereken birkaç nokta vardır. Gri su geri kazanım sisteminde kullanılan tanklarda oluşabilecek kokuların önlenmesi için havalandırma hattı bulunmalıdır. Sistemin nereye kurulacağı ile ilgili olarak, taşma çıkışı geri su akış seviyesine göre tasarlanmalıdır. Eğer mobil konut, kanalizasyon altyapı sistemine sahip ise sisteme kanalizasyon suyunun teması önlenmelidir. Tamir, bakım ve temizlik için motorize kapakçık, pompa, filtre gibi tüm mekanik ekipmanlar kolay erişilebilir bir yerde olmalıdır. Kirli ve temiz su depolama kapasiteleri titizlikle belirlenmelidir. Burada kullanım suyu ile gri su üretimi arasında bir denge bulunması gerekmektedir. Depolar direkt gün ışığına maruz kalmamalı, kaldığı takdirde yosunlaşma sorununa karşı önlemler alınmalıdır (Karahan, 2009: 1162).

Gri suyun yeniden kullanımı için önemli gri su arıtma teknolojileri aşağıdaki gibi sınıflandırılıp karşılaştırılabilir (Üstün ve Tırpancı, 2015: 124) (Şekil 4):

- Yapay Sulak Alan (CW),

- Döner Biyolojik Reaktörler (RBC),

- Ardışık Kesikli Rektörler (SBR),

- Membran Biyoreaktörler (MBR),

- Elektrokoagülasyon (EC),

- Fotokatalatik Oksidasyon. 


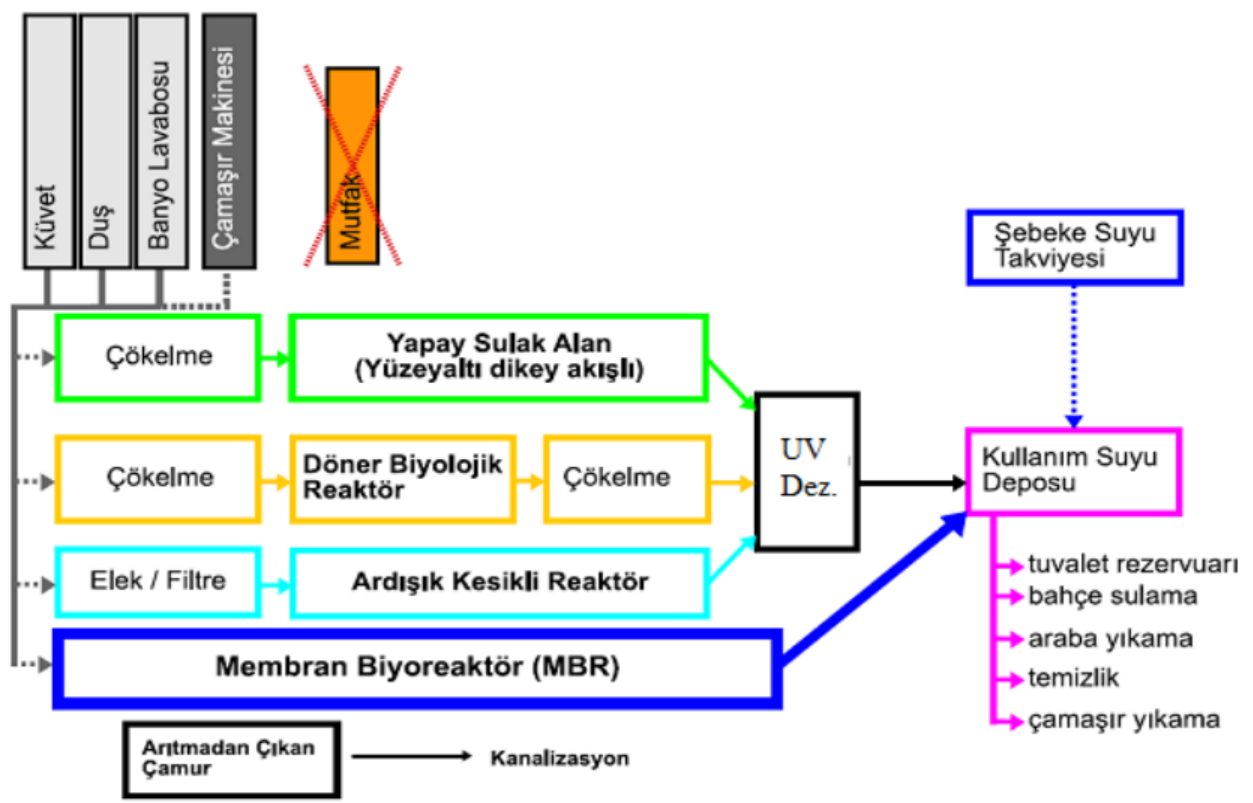

Şekil 4. Gri Su Arıtma Teknolojilerinin Karşılaştırılması (Üstün ve Tırpancı, 2015: 124)

Evsel atık sularının fosseptik atığından meydana gelen bölümünü siyah su oluşturur. Atık su içerisinde de bulunan azot, en ciddi kirlilik etkisine sahip olan ve içme suyundan temizlenmesi en zor olan maddedir. Atık sudaki azotun \%90'ı siyah sudan kaynaklanır. Bu nedenle, siyah ayrıştırılıp yeniden kullanılması çok daha zordur. Rezervuar suyundan meydana gelen siyah suyun arıtıması, biyolojik arıtma, oksijen arıtma, ultrafiltrasyon, klorlu arıtım, ultraviyole dezenfeksiyon gibi çeşitli ayrıştırma aşamalarından geçerek yapılır (Karahan,2009: 1156)

- Yağmur Suyu Toplama Sistemleri:

Yağmur suyu toplama ve depolama işlemi uzun yıllardır kullanılan bir sistemdir. Birçok ülkede geleneksel evlerde kullanılan çatılardan yağmur suyunun toplandığı ve ev içi kullanım için kullanıldığı tanklar, günümüzün çevre dostu mobil konutlarında da arıtma sistemleri ile modernize edilmiş ve desteklenmiştir. $\mathrm{Bu}$ sistemler, esasen herhangi bir şebekeden uzakta bulunan mobil evlerde ve yıkım sonucu su şebekesinin kullanılamaz hale geldiği bir doğal afet sonrasında verimli bir şekilde kullanılabilir. Mobil konutlar, coğrafi koşulların elverdiği ve yıllık yağış miktarlarının yüksek olduğu bölgelerde su temin etmede tatlı su kaynaklarını ve yağmur sularını sıklıkla tercih etmektedirler.

Yağmur suyu toplama, yağmur suyunun geçirimsiz su yakalama ya da tutma yüzeylerinden tutularak, iletim kanalları (oluklar ve borular) vasıtasıyla depolama alanına taşınması, kullanım amacının belirlenmesi ve uygun tanklarda depolanması ile oluşturulan bir sistemdir (Şekil 5). Yağmur suyu toplama sistemi aşağıdaki altı bileşen ile ifade edilebilir (Che-Ani and etc.,2009:134) :

- Su tutma veya yakalama yüzeyleri

- İletim kanalları (Oluk ve borular)

- Oluk süzgeçleri, ayıraçlar ve ana filtreler

- Depolama tankları

- Dağıtma sistemi

- Arıtma ve su kalitesi sistemi 
Mobil konutlarda yağmur suyu, çatı yüzeyinden oluklara, oluklardan da yağmur suyu inişi boruları vasıtası ile depoya aktarılmaktadır. Bina dışında ve toprak altında bulunan depoda rezerv edilen yağmur suyu araba yıkama, bahçe sulama, çevre temizliği, rezervuar, çamaşır yıkama vb. işlerde kullanılmakta ve ciddi su tasarrufları elde edilmektedir.

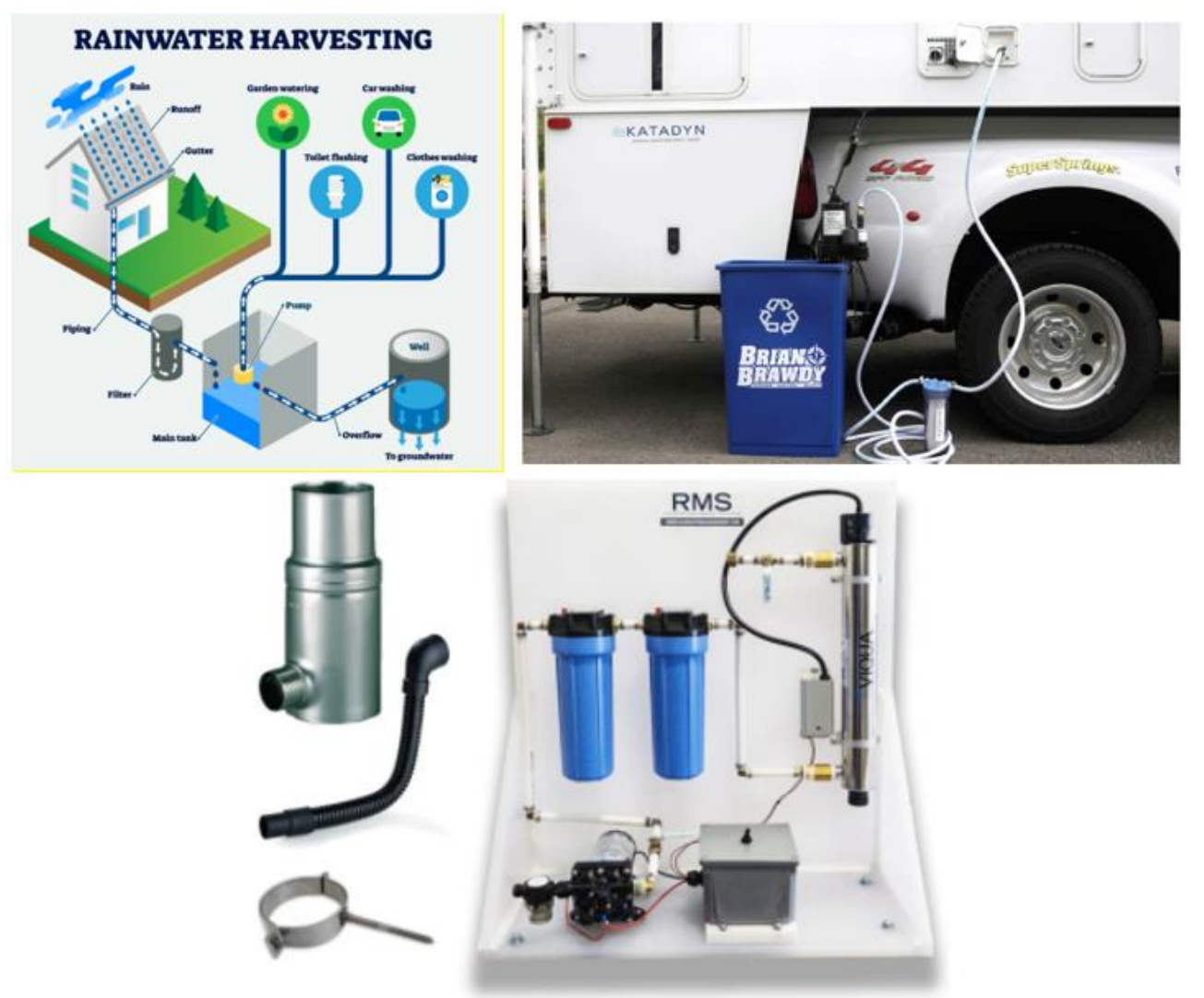

Şekil 5. Mobil Konutlarda Yağmur Suyu Toplama (URL-4; Akbaş, 2010: 83; URL-5)

- Doğal peyzaj uygulamaları

Günümüzde mobil konutlar genellikle şehrin kalabalığı, gürültüsü ve kirliğinden kaçıp doğaya sığınma ihtiyacında olan kullanıcılar tarafından tercih edilmektedir. $\mathrm{Bu}$ bağlamda yeşilin içinde konumlandırılan mobil konutlarda sadece konut çevresinin peyzaj bakımlarının yapılması yeterlidir. Mevcut bitki örtüsünden ayrıca yapının serinletilmesi, aydınlatılması, soğuktan korunması, gölgeleme ve taze hava ihtiyacı için de faydalanılabilir. Tercih edilecek alanın koşullarına göre daha az su ve bakım gerektiren endemik bitkiler seçilmeli, ekim veya dikim alanları önceden planlanmalıdır. Bitkilerin su intiyacına göre gruplandırılması, buharlaşmanın azaltılması, yabancı ot büyümesinin önlenmesi ve toprak sıcaklığının dengelenmesi adına önlemler alınmalıdır. Sulama için temiz su yerine yağmur suyu toplama sistemleri veya gri suyun geri dönüşümü ile elde edilen sular kullanılabilir. Bitkinin ihtiyacı olduğunda damla sulama, toprak altı sulama, otomatik zaman ayarlı sulama sistemleri gibi suyu etkin kullanabilen yöntemler tercih edilmedir (Cook and VanDerZanden, 2010: 15).

- Su tüketiminin azaltılması (Su Tasarrufu Sağlayan Ekipman Kullanma) Mobil konutlarda su kullanımının azaltılması su tasarrufu sağlayan batarya, vitrifiye ve armatürlerin kullanılması ile mümkün olmaktadır. Bu ekipmanlara 
örnek olarak susuz pisuar, kompost tuvalet, çift kademeli rezervuar, havalandırıcılı duş başlığı, fotoselli bataryalar verilebilir. Ayrıca düşük debili bağlantıların, düşük akımlı havalandırıcılı başlıkların ve perlatörlerin tercih edilmesi, kaçakların hemen tespiti ve tamiri, su tasarrufu sağlayacak beyaz eşyaların kullanımı su etkinliğini arttırmaktadır (Çakır Kıasıf, 2020: 109). Kısa süreli kullanılan mobil konutlarda kasetli portatif tuvaletler sıklıkla tercih edilmektedir. Depo içerisinde biriken atıkların kimyasal ayrıştırıcılar ile kokusuzrenksiz bir sıvıya dönüştürülmesi ve uygun yere boşaltılması prensibine dayanan sistemde doğa dostu kimyasalların tercihi büyük önem taşımaktadır. Mobil konutlarda diğer tercih edilmesi önerilen tuvalet tipi kompost tuvaletlerdir (Şekil 6). Kompost tuvaletler doğru kullanıldığında koku ve hijyen sorunu yaşatmaz. İnsan atığından kaliteli gübre üreterek hem toprağın veriminin artırıması hem de tonlarca suyun kurtarılması sağlanır. Ancak bunun için katı atığın kapalı bir ortamda tutulması, toprak içerisinde suyunu kaybederek dehidre olması ve azot dengesinin sağlanması gerekmektedir (Şengül, 2019: 131-132).

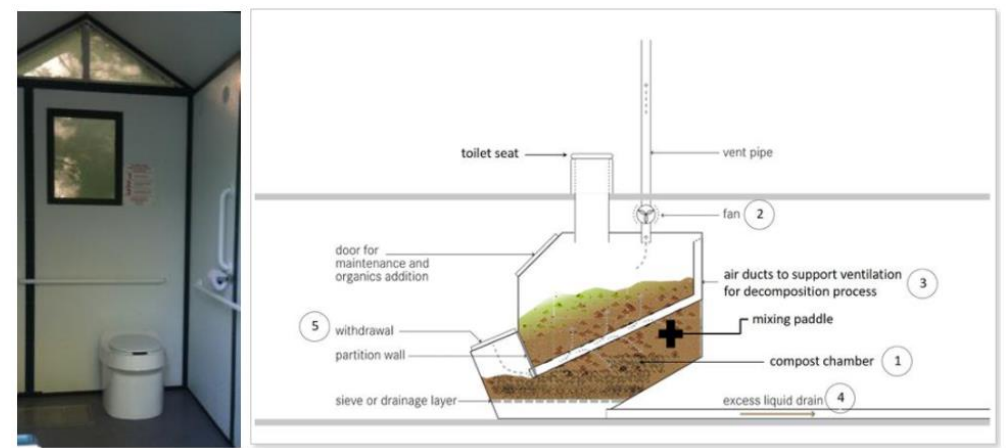

Şekil 6. Mobil Konutlarda Kompost Tuvalet Uygulaması (URL-6)

Aşağıdaki çizelgede mobil konutta yaşayan 4 kişilik bir ailenin su kullanım oranları analiz edilmiştir. Bu analizde Çevre ve Şehircilik Bakanlığının evlerde ve işyerlerinde daha az su kullanımına ait çalışmadan faydalanılmıştır (URL-7). Su etkin sistemlerle donatılmış bir mobil konut ile klasik bir mobil konut su performansı bağlamında karşılaştırılmış ve ciddi tasarruflar elde edilebileceği görülmüştür (Çizelge 3).

Çizelge 3. Mobil Konutta Klasik Sistemler ile Su Etkin Sistemlerin Karşılaştırılması (Çizelge yazarlar tarafından oluşturulmuştur)

\begin{tabular}{|l|l|l|l|}
\hline $\begin{array}{l}\text { Mobil Konutta Yıllık Su } \\
\text { Tüketimi }\end{array}$ & $\begin{array}{l}\text { Klasik } \\
\text { Sistemler } \\
\text { Tercih } \\
\text { Edildiğinde (It) }\end{array}$ & $\begin{array}{l}\text { Su Etkin } \\
\text { Sistemler } \\
\text { Tercih } \\
\text { Edildiğinde } \\
\text { (It) }\end{array}$ & $\begin{array}{l}\text { Yıllık } \\
\text { Tasarruf } \\
\text { Miktarı (It) }\end{array}$ \\
\hline Rezervuar Kullanımı & 46720 & 11680 & 35040 \\
\hline Duş Kullanımı (5 dak.) & 98550 & 27375 & 71175 \\
\hline $\begin{array}{l}\text { Mutfak-Banyo-Tuvalet } \\
\text { Musluklarından (Duş hariç) }\end{array}$ & 119720 & 59860 & 59860 \\
\hline Bulaşık - Çamaşır Yıkama & 32136 & 8580 & 23556 \\
\hline Bahçe Sulama & 40000 & - & 4000 \\
\hline Toplam & 337126 & 107495 & $\mathbf{2 2 9 6 3 1 ~ I t}$ \\
\hline
\end{tabular}


Buna göre (Çizelge 3):

- Rezervuar kullanımında günde ortalama 8 kez (kişi başı 2 kez) kullanıldığı düşünülerek; klasik 16 It hacmindeki bir rezervuar ile yıllık 46720 It su tüketimi, su etkin 4lt hacme sahip ultra düşük rezervuar ile yıllık 11680 It su tüketimi yapılacağı görülmüştür. Bu rezervuarlardan yıllık 35040 It suyun kurtarılabileceği anlamına gelmektedir.

- Duş kullanımında suyun etkin kullanımında 2 önemli kıstas bulunmaktadır. Bunlardan ilki duş yapma süresi, ikincisi de duş başlığı seçimidir. İdeal duş süreci 5 dakikadır. Klasik duş başlığı ile dakikada 15-20 It, düşük debili havalandırıcılı duş başlığı ile dakikada 3,5-7,6 It su tüketilmektedir. Buna göre günde 3 kişinin duş aldığı düşünülürse klasik duş başlığı ile ortalama 98550 It, su tasarruflu duş başlığı ile 27375 It su harcanmaktadır. Bu duş kullanımında 71175 It suyun kurtarılabileceği anlamına gelmektedir.

- Mutfak, banyo ve tuvaletlerde yemek hazırlama, temizlik, yüz yıkama, diş fırçalama, taharet, tıraş olma gibi faaliyetler için musluklardan akan su kullanılmaktadır. Klasik musluklar dakikada 8-27 It. su harcarken, düşük debili havalandırıcılı musluklar dakikada 1,8-4,5 It. su harcamaktadır. Su etkin sistemlerin tercih edilmesi ile mutfak, banyo ve tuvaletlerdeki musluklardan akan sudan $\% 50$ oranında tasarruf elde edilerek kişi başı ortalama 41 It. suya intiyaç duyulduğu belirlenmiştir. Bu klasik musluklar ile 119720 It. su tasarruflu musluklar ile 59860 It. suyun tüketilmesi ve 59860 It. suyun kurtarılması anlamına gelmektedir. Kişisel temizlik için tüm süreç boyunca (diş fırçalama, tıraş olma gibi) musluğun açık bırakılması ciddi su kayıplarının yaşanmasına neden olmaktadır. Bu yüzden bireyde su bilincinin oluşturulmasının ve sensörlü sistemlerin kullanılmasının önemi büyüktür.

- Bulaşıkların bulaşık makinesi ile yıkanması sudan ciddi oranda tasarruf elde edilmesini sağlar. Bir bulaşık makinesi her yıkamada yaklaşık 15lt su tüketmekte ve elde yıkamaya oranla 111 It suyun kurtarılmasına neden olmaktadır (URL-8). Haftada 3 kere bulaşık makinesinin çalıştırıldığını varsayıp elde yıkama ile kıyaslanırsa yılda bulaşık makinesi ile 2340lt, elde yıkama ile 19656 It su tüketilir. Bulaşık makinesi ile yılda 17316 It suyu kurtarabilir.

Çamaşır makinelerin tercihinde ise suyu ve enerjiyi etkin kullanabilen modeller tercih edilmelidir. $5 \mathrm{~kg}$ yıkama kapasiteli klasik bir çamaşır makinesi her yıkamada 80 It su kullanırken, su etkin bir çamaşır makinesi 40 It ile yetinilebilmektedir (URL-9). Haftada $3 k e z$ çamaşır yıkanıldığı düşünülürse yüksek su tüketimi yapan makine ile yıllık $12480 \mathrm{It}$, su tasarruflu makine ile 6240lt su tüketilir. Bu da yılda 6240 It. suyun kurtarılması anlamına gelmektedir.

- Bahçe sulama için ise $100 \mathrm{~m}^{2}$ bahçe baz alınarak İstanbul ili için yıllık yağış oranı göz önünde tutularak senede 80 gün sulama yapılması ön görüldüğünde klasik bir mobil konutta şebeke suyu kullanımında günlük 500 It su tüketilirken ve yıllık bazda ise bu tüketim 40000 It'yi bulmaktadır. Yağmur suyu veya gri suların kullanıldığı su etkin sistemler tercih edildiği takdirde sulama için herhangi bir su israfı yapılmamaktadır. 


\section{Sonuç}

Küresel iklim değiş̧ikliği, nüfus artışı, kentleşme, sanayileşmenin etkisiyle kısıtlı olan tatlı su kaynakları zarar görmekte ve yetersiz kalmaktadır. Avrupa Birliği dünyadaki su krizine çözüm bulabilmek adına sürdürülebilir su politikaları üzerine çalışmakta, uluslararası su stratejileri belirlemekte ve entegre su yönetimini benimsemektedir. Yapı sektöründe ise suyun etkin kullanımı ve doğru yönetilmesi adına sürdürülebilir yöntemler kullanılmakta ve ciddi su tasarrufları elde edilmektedir. Çalışma kapsamında istenildiği zaman konum değiştirebilen, doğa ile uyumlu ve farklı çevre koşullarına adaptasyonu yüksek olan mobil konutlar ele alınarak su etkinliği değerlendirilmiştir. Mobil konutlarda; gri suların tekrar kullanımı, yağmur sularının değerlendirilmesi, doğal peyzaj uygulamaları ve su tasarruflu batarya, vitrifiye, rezervuar, duş başlıkları, sızıntı dedektörleri ve akış düzenleyici ekipmanlarla ciddi su tasarrufları elde edilebileceği görülmüştür. Mobil konutlar için ele alınan su etkin sistemler diğer yapı tipleri için de uygulanabilmektedir.

Çalışma kapsamında mobil konutta yaşayan 4 kişilik çekirdek bir ailenin ortalama yıllık su tüketimi incelendiğinde klasik sistemler kullanıldığında 337126lt, su etkin sistemler tercih edildiğinde 107495 It su tüketildiği görülmüştür. Bu durum yıllık bazda 229631 It.lik bir suyun kurtarılması anlamına gelmektedir. Mobil konutlar için ele alınan bu su etkin sistemler diğer tüm yapı tipleri için de kullanılabilmektedir. Bu nedenle bu çalışma diğer yapı tipleri için de örnek teşkil etmektedir. Özellikle daha yüksek su tüketimine sahip turizm yapıları, su sporları tesisleri ve yüksek yoğunluklu konut tipleri için daha yüksek oranlarda su tasarrufları elde etmek mümkündür. Bu durum su sıkıntısı yaşayan Türkiye'de suyun korunumu için büyük önem arz etmektedir. Ulusal ve uluslararası platformda su doğru yönetilemezse ekolojik yapı telafisi olmayan hasarlar alacak ve sürdürülebilirlik sağlanamayacaktır. Bu yüzden yasa ve yönetmeliklerle özellikle belli bir metrekarenin üzerinde olan yapılarda suyun etkin kullanımı adına bazı uygulamalar zorunlu kılınmalıdır. Suyun israf edilmesi ve doğru kullanılamaması durumunda ciddi yaptırımlar uygulanmalıdır. Ayrıca su etkin sistemlerin tüm yapı tiplerinde uygulanabilmesi adına devlet teşvikleri arttırılarak talep artışı sağlanmalıdır.

\section{Kaynaklar}

Akbaş, Emre, "Ekolojik Mobil Konutların Teknolojisi ve lç Mekân Düzenlemelerinin Incelenmesi", Yüksek Lisans Tezi, Mimar Sinan Güzel Sanatlar Üniversitesi Fen Bilimleri Enstitüsü, İstanbul, 2010.

Aküzüm, Turhan, Çakmak, Belgin, ve Gökalp, Zeki, "Türkiye'de Su Kaynakları Yönetiminin Değerlendirilmesi”, Tarım Bilimleri Araştırma Dergisi, 3 (1), 2008, s.67-74.

Boyjoo, Yash, Pareek, Vishnu. , Ang, Ha Ming, "A Review Of Greywater Characteristics and Treatment Processes", Water Science \& Technology, 67, 2013, s.1403-1422.

Che-Ani, Shaari, Sairi, Zain, Tahir, "Rainwater Harvesting as an Alternative Water Supply in the Future", European Journal of Scientific Research, Vol.34 No.1, 2009, p.132-140

Cook, W. Thomas, VanDerZanden, Ann Marie, "Sustainable Landscape Management: Design, Construction, and Maintenance", John Wiley \& Sons, Inc., Hoboken, New Jersey, 2010.

Çakır, Gözde, "Study of Climate Change on the subject of Sustainable Development on a Global Scale", GreenAge Symposium, Mimar Sinan Fine Arts University, Faculty of Architecture 26-27April 2012, Istanbul, Türkiye, s.448-457. 
Çakır Kıasıf, Gözde, "Su Yönetimi ve Yapı Endüstrisindeki Su Etkin Otel Tasarımları: İstanbul'daki LEED Sertifikalı Sürdürülebilir Otel Karşıllaştırmaları”, MTD Uluslararası Hakemli Tasarım ve Mimarlık Dergisi, Sayı: 19, 2020, s.97-133.

Jaglarz, Anna, "Sustainable Development in the Concepts of Modern Bathrooms", 6th International Conference on Applied Human Factors and Ergonomics and the Affiliated Conferences, Procedia Manufacturing 3, 2015, p.1638-1645.

Kadıoğlu, Mikdat, “Küresel İklim Değişimi ve Türkiye”, Güncel Yayıncılık, İstanbul, 2007

Karahan, Abdullah, "Gri Suyun Değerlendirilmesi", IX. Ulusal Tesisat Mühendisliği Kongresi, 06-09 Mayıs, Tepekule, 2009, s.1155-1164.

Karalar, Rıdvan, Kiracı, Hakan, "Çevresel Sorunlara Karşı Bir Çözüm Önerisi Olarak Sürdürülebilir Tüketim Düşüncesi”, Dumlupınar Üniversitesi Sosyal Bilimler Dergisi, 30, 2011, s.63-76.

Karaoğlu, Öznur, "Mobil Mekanların İç Mekan Organizasyonu ve Örneklerle Mobil Ofis Tasarımlarının Analizi”, Yüksek Lisans Tezi, Hacettepe Üniversitesi Güzel Sanatlar Enstitüsü, Ankara, 2014.

Louche, Dan, "Tiny House Design \& Construction Guide", First Edition, Copyrighted Material, Tilt Dev., 2012.

Roaf, Sue, Fuentes, Manuel, Thomas, Stephanie, "Ecohouse 2: A Design Guide", Architectural Press, UK., 2003.

Sev, Ayşin, "Sürdürülebilir Mimarlık”, YEM, 1.Baskı, İstanbul-Türkiye, 2009.

Schaefer, Anja, Crane, Andrew, "Addressing Sustainability and Consumption", Journal of Macromarketing, Vol.25, No.1, 2005. https://doi.org/10.1177/0276146705274987

Şahin, Nazlı İpek, Manioğlu, Gülten, "Binalarda Yağmur Suyunun Kullanılması", X. Ulusal Tesisat Mühendisliği Kongresi, 13-16 Nisan, İzmir, 2011, s.529-542.

Şengül, Gözde, "Mobil Konut Bağlamında, Zamanın Değişen Ihtiyaçlarına Karşı Mekansal Arayışlar: Tiny House Örneği”, Yüksek Lisans Tezi, Marmara Üniversitesi, Güzel Sanatlar Enstitüsü İç Mimarlık Ana Sanat Dalı, İstanbul, 2019.

Taşkesen, Mehmet Gökberk, "Mobil Konutlar ve İç Mekan Biçimlenişi”, Yüksek Lisans Tezi, T.C. Başkent Üniversitesi, Sosyal Bilimler Enstitüsü, Ankara, 2019.

T.C. Kalkınma Bakanlığı, "On Birinci Kalkınma Planı (2019-2023)- Su Kaynakları ve Güvenliği Özel Ihtisas Komisyonu Raporu”, Ankara, 2018.

Erişim Adresi (01.11.2021): https://www.sbb.gov.tr/wpcontent/uploads/2020/04/SuKaynaklariYonetimi_ve_GuvenligiOzellhtisasKomisyonuRa poru.pdf

T.C. Orman ve Su İşleri Bakanlığı-2.Ormancılık ve Su Şurası, "Su Kaynaklarının Geliştirilmesi ve Hidroloji Çalışma Grubu Raporu", 5-7 Mayıs 2017, s.27-33. 
Usta, Ayhan, "Türkiye'deki Su Potansiyelinin Belirlenmesi Üzerine Bir Araştırma”, The Journal of Global Engineering Studies, 3(2), 2016, s.01-09.

Üstün, Gökhan Ekrem, ve Tırpancı, Ayşenur, "Gri Suyun Arıtımı ve Yeniden Kullanımı", Uludağ Üniversitesi Mühendislik Fakültesi Dergisi, Cilt: 20, Sayı:2, Bursa, 2015. doi: 10.17482/uujfe.79618.

Yılmaz, Ayşe, "Küresel Isınmanın Dünya Su Rezervleri Üzerindeki Etkileri", Kent Akademisi, Kent Kültürü ve Yönetimi Hakemli Elektronik Dergi, Cilt:8, Sayı:2, 2015.

URL-1: https://webdosya.csb.gov.tr/db/bolu/icerikler/su-20180222083149.pdf , Erişim Tarihi: 05.11.2021, 17:13.

URL-2: https://www.dsi.gov.tr/Sayfa/Detay/1344 , Erişim Tarihi: 03.11.2021, 11:25.

URL-3: https://data.tuik.gov.tr/Bulten/Index?p=Belediye-Su-Istatistikleri-2018-30668, Erişim Tarihi: 05.011.2021, 17:43.

URL-4: https://tr.depositphotos.com/vector-images/rainwater-harvesting-system.html , Erişim Tarihi: 04.11.2021

URL-5: $\quad$ https://rainwatermanagement.com/collections/tiny-houseapplications/products/tiny-house-rainwater-harvesting-package , Erişim Tarihi: 04.11.2021, 11:09.

URL-6:

https://serc.carleton.edu/integrate/teaching_materials/energy_sustain/student_material s/composting_toil.html, Erişim Tarihi: 05.11.2021, 15:38

URL-7: http://www.cevresehirkutuphanesi.com/assets/files/slider_pdf/ltJEcnrc4BA.pdf, Erişim Tarihi: 15.11.2021, 12:47

URL-8: $\quad$ https://finish.com.tr/blogs/bulasik-tuyolari/bulasik-makinesi-nasil-su-tasarrufusaglar , Erişim Tarihi: 15.11.2021, 18:18

URL-9: https://www.servisi.com.tr/camasir-makinesi-ne-kadar-su-kullaniyor, Erişim Tarihi: $15.11 .2021,18: 40$ 